\title{
RESEARCH EXCELLENCE IN UK DENTISTRY
}

A. D. Walmsley

Scientific Advisor to the British Dental Association

The BDJ Upfront section includes editorials, letters, news, book reviews and interviews. Please direct your correspondence to the News Editor, Kate Quinlan at the BDJ, The Macmillan Building, 4 Crinan Street, London, N1 9XW or by email to k.quinlan@nature.com

Press releases or articles may be edited, and should include a colour photograph if possible.
$\mathrm{D}$ id you know that research from our dental schools is world leading? Are you aware that dentistry in the UK is rated as internationally excellent? Good news, but there is still work needed to ensure it is kept this way.

Late last year the results of the Government's research excellence framework (REF) were announced which are of huge importance for all UK universities. Dentistry as a university subject was part of this assessment but what do the results mean? As background, the REF assessed the quality of research in UK higher education institutions from 2008-14. The review was carried out in 36 subject-based units of assessment (UoAs). Dentistry was in panel UoA3, which consisted of allied health professions, dentistry, nursing and pharmacy. Each panel assessed the quality of research in the following three areas. Any form of research 'output' including publications such as journals, chapters in books etc published in the assessment period made up 65\% of the scores. The second area was 'impact' (20\%) assessing how the research has provided benefit to the UK and beyond, for example by improvements in patient health or quality of life, positive effects on the economy and industry and/or how we perform clinically. Finally, the research 'environment' was assessed (15\%). This part of the assessment refers to the approach that the institution provides to resources and infrastructure for the research to take place. As the REF was being formulated the BDA fed into the discussions on shaping the UoA3 unit of assessment.

Dental institutions were tasked to ensure there was a balance between high quality research and the number of staff they returned. The outputs

'The jewel
in the
crown for
any den-
tal school
is the vital
ingredient
of research
activity...'

and publications being assessed were judged at world leading $\left(4^{*}\right)$, internationally excellent (3*), nationally leading $\left(2^{*}\right)$ and nationally excellent $\left(1^{*}\right)$. In reality, $3^{*}$ and $4^{*}$ outputs were the targets, especially as government funding was going to be linked to those institutions that gained the highest scores in these areas. Dental schools' main activities revolve around teaching and learning to develop the future generation of dentists, and some dental schools did not return in UoA3, having moved towards becoming teaching focussed establishments. Dental schools also undertake significant postgraduate training and many of the clinical academics provide an important NHS service.

However, the jewel in the crown for any dental school is the vital ingredient of research activity. Innovation and discovery often lead to new advances in our subject area. Whether these are biological, biomaterials or other clinical sciencerelated subjects, they enhance the reputation and practice of dentistry. The benefits that accrue from research findings in the UK impact on dental practice globally and ultimately on patient care. In dental schools, we rely heavily on our non-clinical research colleagues to provide our scientific basis and to assist this most schools forge clinician-scientist partnerships, which are highly prized. As dentists we are a very adaptable bunch of people and our training allows us to forge interdisciplinary links with other specialities. It is this entrepreneurial spirit that makes dentistry unique. Therefore, it is with great pride that we are able to report that dentistry performed extremely well in the REF. All schools that were returned had their research profile mentioned at University level. Our outputs were significantly at the $3^{*}$ and $4^{*}$ level. Our impact to the UK economy is substantial and this was also highlighted. UK dentistry should be proud of these results and in spite of all the political twists and turns that have occurred to our profession over the last five years, we now have something to shout out about that demonstrates the depth of our research and contribution to the country.

However, Bryan Forbes, the British actor, was quoted in the Observer newspaper (1971) stating that 'nothing recedes like success' So dental research cannot stay still, our researchers need to maintain and build on this high level of activity. The contributions of full-time and part-time GDP teachers together with our NHS inter-professional colleagues are essential components to the lifeblood of a dental school. They allow the space for the researchers to contribute to the impact of the school. So the REF results are a team effort involving all strands of dental care within a school. We are all acutely aware of the future challenges that UK dentistry will be facing, especially with the tensions of time and money whilst maintaining the highest standards that will ultimately benefit our patients. In a recent statement, Sir Paul Nurse President of the Royal Society called 'for greater funding to the sciences, especially now that the green roots of economic recovery were beginning to show in the UK'. This must also include dentistry that is now demonstrably a high ranked science subject.

But for now, let us shout out the good news and next time that people mention the state of British dentistry and our dental schools then we can reply that we are world leading in dental research.

DOI: 10.1038/sj.bdj.2015.101 